\title{
Festa de Nossa Senhora da Conceição: Evento como Atrativo Religioso de Luís Correia - PI
}

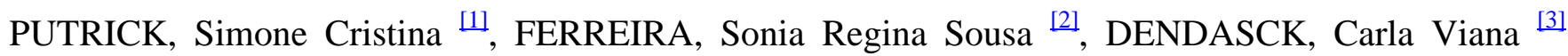
, SBIZERA, Carmem Lúcia Giacomeli Aoki ${ }^{[4]}$

PUTRICK, Simone Cristina; et.al. Festa de Nossa Senhora da Conceição: Evento como Atrativo Religioso de Luís Correia - PI. Revista Científica Multidisciplinar Núcleo do Conhecimento. Ed. 06, Ano 02, Vol. 01. pp. 270-281, Setembro de 2017. ISSN:2448-0959, Link de acesso: https://www.nucleodoconhecimento.com.br/ciencia-da-religiao/evento-como-atrativo-religioso, DOI: 10.32749/nucleodoconhecimento.com.br/ciencia-da-religiao/hermeneutica-e-aspectos-legais

\section{RESUMO}

Considera-se turismo religioso, visitas a locais de atração mística que suscitam a fé e mantenham total ou parcial utilização dos equipamentos turísticos das localidades onde se realizam. Esta forma de turismo vem ganhando forças nos últimos anos, ganhando sincretismo e hibridismo em sua composição para atrair o máximo de público possível. Esta pesquisa tem como objetivo identificar o evento intitulado Festa de Nossa Senhora da Conceição realizada na cidade de Luís Correia - PI como um atrativo turístico religioso. A pesquisa possui abordagem qualitativa e enquadra-se no método de caráter exploratória/descritiva. Foram utilizadas pesquisas bibliográficas, documental, pesquisa de campo participante e entrevistas. Os dados foram coletados na Igreja Matriz de Nossa Senhora da Conceição, junto à Secretaria da Paróquia além dos moradores da cidade de Luís Correia e de outras comunidades próximas. Os resultados dos objetivos apontam a Festa de Nossa Senhora da Conceição como atrativo turístico, capaz de provocar deslocamento, sendo elemento pertencente à história e a cultura do lugar.

Palavras-Chave: Eventos, Religiosos, Atrativos.

\section{INTRODUÇÃO}

No Brasil, a obrigatoriedade histórica de uma religião oficial durante a colônia até o fim do império foi o fator primordial para manutenção dos valores católicos em toda extensão do território brasileiro. Em países de formação religiosa católica, a dinâmica que caracterizou a sua formação tem características que os fizeram diferentes entre si, apesar de terem as origens comuns na Igreja Católica Apostólica Romana. 
Essas diferenças foram construídas inicialmente a partir da instalação de Ordens Religiosas (Salesianos, Franciscanos, Beneditinos, entre outras), que fizeram sedimentar este ou aquele aspecto da religiosidade local ou regional, os quais com o passar dos anos e séculos, tornaram-se características culturais das comunidades (Ribeiro, 2010, p.2).

Além disso, o catolicismo no Brasil apresenta-se sincrético e, em alguns aspectos híbridos, aderindo outras tradições em sua formação e ordenamento, principalmente de origens africanas e indígenas, bem como, movimentos que visam atender um grupo específico, como por exemplo a Renovação Carismática e as Comunidades Eclesiais de Base ( Pereira, 2012). Assim, a capacidade do catolicismo na tentativa de atender a complexidade do campo religioso brasileiro, possibilita que embora com número de fieis decrescente, a igreja apresente-se ainda como a maior e mais influente no Brasil, especialmente no nordeste.

Neste sentido as festas populares, que normalmente fazem parte das atividades religiosas geralmente compartilham o lado religioso e o profano. Sendo que, ao mesmo tempo em que pratica a fé, satisfaz também a necessidade de lazer e entretenimento, atuando então dentro da complexidade religiosa já aludida acima.

A cidade de Luís Correia no estado do Piauí tem sua população de maioria católica, possuindo grande parte dos $66 \mathrm{~km}$ de praia do estado, sendo conhecida e visitada pelo segmento de turismo de sol e mar (IBGE, 2017). No entanto, não somente este tipo de turismo a caracteriza, mas também, as festas religiosas populares, que acabam por ser uma grande atração da região.

Por tudo isso, este trabalho faz uma reflexão a partir da Festa de Nossa Senhora da Conceição, visa-se verificar o que caracterizaria um atrativo de turismo religioso: Seriam visitas a lugares apenas com atração mística ou que suscitem a fé? Ou há necessidade de haver a utilização total ou parcial dos equipamentos turísticos de uma cidade? O presente projeto tem como objetivos, identificar se a Festa enquanto evento religioso pode se caracterizar como um atrativo, descrevendo-a, identificando seus participantes, conhecendo as motivações de seus frequentadores, apresentando-a como elemento pertencente à história e a cultura de Luís Correia.

\section{TURISMO E EVENTOS}

Os eventos são atividades de entretenimento, com grande valor social, cultural e, sobretudo, histórico. Suas atividades constituem um verdadeiro mix de marketing, entretenimento, lazer, artes e negócios. E tal é a sua importância no contexto social, cultural, econômico e político de uma cidade e região, em alguns casos até mesmo de um país, que podemos denominá-los de agentes do patrimônio histórico-cultural (MELO 2005).

Diferentemente de outras atividades, os eventos podem ser realizados em qualquer época do ano e em qualquer lugar. O organizador, seja ele experiente ou não, é quem vai decidir a proporção, o público e as "ferramentas" de marketing que deseja e necessita usar. Esse tipo de decisão vai fazer parte do que se tem chamado de economia criativa, e passa então, a ser uma ferramenta para o desenvolvimento local (Reis, 2007).

Os eventos são atividades de entretenimento no momento que ajudam a distrair, divertir pessoas, 
principalmente nos dias de hoje, onde o indivíduo exerce vários tipos de atividades e estão expostos a diversos níveis de estresse e preocupações. Tem valor social, ao fazer pessoas com valores e realidades diferentes, juntem-se num mesmo ambiente e compartilhe a mesma experiência mesmo que formas diferentes. Podem se tornar históricos ao atrair um número recorde de público, ao ser pioneiro em determinada modalidade ou segmento ou ainda por ser fixo e tradicional na cidade ou região onde se realiza. Além de movimentar e atrair pessoas quando bem divulgado, geram emprego e renda nos lugares em que se realizam.

Diferentemente dos monumentos e demais equipamentos urbanos, dotados de valor histórico, os eventos representam:

[...] a memória viva de uma cidade. São agentes formadores de um novo ethos social. Eventos de sucesso criam novos tipos de relações entre as pessoas, novos jargões linguísticos, palavras de ordem, fomentam paixões, desenvolvem hábitos e costumes e definem novos estilos de ser e de viver (op cit, p. 53).

Na cidade de Luís Correia, o aprimoramento na organização da Festa de Nossa Senhora da Conceição é vista "como uma forma de buscar os fiéis perdidos e arrebanhar novos, além de fortalecer os laços da comunidade, e não deixar acabar esta Festa tradicional que consegue reunir pessoas de toda a comunidade local e vizinha”, conforme o que se identifica no discurso do pároco local.

A relação turismo e patrimônio são elementos muito importantes na vida e na economia de muitas cidades, sejam elas históricas ou não. Muitas delas, tanto no Brasil como no mundo, são conhecidas pelas belezas de seu patrimônio cultural ou histórico, imaterial ou material. Quando se trata de patrimônio, o turismo muito tem contribuído para que importantes processos de recuperação aconteçam. No Brasil, isso acontece porque o patrimônio histórico edificado é muito rico, com traços deixados pelos muitos povos que por aqui estiveram ao longo dos séculos.

A origem da palavra "patrimônio" está no latim, patrimonium, que significava a herança, os bens familiares. Hoje, patrimônio possui vários significados e depende da abordagem que é feita (Lohmann e Netto, 2008).

O turismo aparece como força motivadora para a preservação do patrimônio ao se considerar que as perspectivas de retorno financeiro através da sua exploração estimulam os investimentos para restauração e conservação dos bens (Bussons et al. 2005). No entanto, o desenvolvimento turístico, assim como outros desenvolvimentos, exige não só investimentos e transformações urbanísticas como requer que se tenha bem presente que um fluxo excessivo de viajantes, sejam eles turistas ou excursionistas, pode produzir efeitos negativos (Portuguez, 2004).

A preservação vem em detrimento do turismo, ao passo que para maioria dos empreendedores, o retorno financeiro é bem mais importante e urgente que a conservação e preservação desses bens. No entanto, é necessário ser pensado as formas de minimizar seus impactos negativos, para que estes possam ser usufruídos ao longo do tempo, tanto pelo investidor, quanto pelo usuário, seja ele turista ou visitante.

Devendo-se levar também em consideração que,

[...] ao visar o risco de que mesmo com a preservação do patrimônio material ocorra a perda da identidade 
cultural. Isso pode acontecer devido à falta de entrosamento entre a população e a cultura. As manifestações podem ser vistas como encenações teatrais objetivando apenas a atração dos turistas, e perdendo a sua verdadeira essência. (Bussons et al. 2005, p.04)

E como forma de evitar que isso aconteça e minimizar os pontos negativos da exploração turística, devese pensar em encontrar alternativas que visem gerar algo como uma educação patrimonial, conscientizando a população sobre a fundamental importância de se preservar os bens para as gerações futuras (Bussons, et al. 2005). Sempre lembrando que é imprescindível ordenar ou classificar todos os bens que compõem o patrimônio, estabelecendo regras de como e onde preservá-los em sua totalidade ou selecionando elementos realmente representativos.

\subsection{O TURISMO RELIGIOSO}

Muitos lugares do Brasil e do mundo são conhecidos por suas devoções, sejam elas oficiais ou populares como Jerusalém, Roma, Juazeiro no estado do Ceará e Aparecida do Norte no estado de São Paulo, tornando-se núcleos receptores importantes em termos de fé e de turismo religioso.

Nos séculos III e IV da era Cristã, os fiéis começaram a cultivar o hábito de viagens de caráter religioso a eremitérios, mosteiros e conventos da Síria, do Egito e de Belém. Também foi o início de uma série de visitas a igrejas e santuários onde se encontravam os restos mortais de mártires e célebres e a locais onde Cristos, seus apóstolos e discípulos passaram, viveram e morreram, além de outros lugares celebrizados por eventos importantes do Antigo Testamento (Andrade, 2004).

Há uma preocupação de muitos autores ao falar de turismo religioso ao citarem as questões do profano e do sagrado se referindo como sagrado às imagens e os templos (igrejas) e o profano caracterizando-se dentre outras coisas nas festas sociais que se realizam após as missas. Sendo que não existe possibilidade de separá-los. Não existe Festa religiosa tendo, como representação do sagrado a imagem dos santos, sem a presença também do profano. É própria do ser humano a necessidade de alimentar tanto a alma, quanto o corpo.

Oliveira (2005, p.326), fala que "um santuário religioso não deixa de ser sagrado porque se tornou turístico, nem deixa de incluir uma série de elementos profanos que estão longe de qualquer vinculação turística direta (comercio, poder, serviços, etc.) ". Estas são questões próprias do turismo religioso, até porque se um descaracterizasse o outro, não haveria a expressão ou segmento de turismo religioso. Quanto ao comércio e os serviços, de fato, podem caracterizar qualquer tipo de atividade que não seja a turística.

Turismo religioso é [...] "o conjunto de atividades com utilização parcial ou total de equipamentos e a realização de visitas a receptivos que expressam sentimentos místicos ou suscitam fé, a esperança e a caridade aos crentes ou pessoas vinculadas a religiões". (Andrade, 2004, p.77).

Há um processo de expansão do turismo religioso que não se confunde com os novos apelos religiosos da sociedade urbano-industrial. Porém, ajusta-se à complexidade humana daquilo que podemos reconhecer como motivação turística (Oliveira, 2005). Talvez, esta seria mais uma ressalva acerca do que seria de fato turismo religioso na busca do conhecimento das diversas motivações de seus adeptos. 
O turismo religioso é um segmento que tem crescido de forma considerável, além de seus aspectos místicos e dogmáticos, as religiões assumem o papel de agentes culturais importantes, em todas as suas manifestações de proteção e valores culturais antigos, de intervenção na sociedade atual e de preservação no que diz respeito ao futuro dos indivíduos e das sociedades (Andrade, 2004).

O turismo religioso como prática de eventos, se caracteriza como um fator de motivação cultural, dando continuação à história e a prática da religiosidade, além de movimentar a economia e gerar emprego direto ou indireto, propiciando infraestrutura, embora básica mais de caráter fixo, ajudando a desenvolver muitas cidades e regiões onde estes se realizam. Hoje temos disponíveis literaturas para organização de ventos espíritas, evangélico, católicos, enfim uma vasta literatura que busca atingir este segmento da área de eventos que cresce cada vez mais.

\section{DESENVOLVIMENTO}

A motivação seja ela pelo lazer ou pela realização espiritual religiosa, têm movimentado milhões de pessoas aos lugares mais inusitados, pessoas que percorrem horas, dias, em condições muitas vezes precárias de transporte. Tudo para chegar aos lugares ditos sagrados. As tradições e a história de um povo podem estar caracterizadas em seus eventos religiosos, quando estes também se tornam patrimônio imaterial de uma cidade ou região.

Essa é a realidade da Festa de Nossa Senhora da Conceição, um evento fixo do calendário da cidade de Luís Correia no estado do Piauí. É uma cidade com 29.146 mil habitantes segundo o Instituto Brasileiro de Geografia e Estatística - IBGE 2010, localizada no menor litoral do Brasil. Sua população de maioria católica, mantém viva a história e a tradição de seu povo através da Festa de Nossa Senhora da Conceição.

Se for estudado qualquer momento da história, é visível o fato de que o ser humano sempre teve certo respeito ou temor pelo divino, pelo sagrado. É imprescindível a necessidade de se dedicar a vida a princípios mais elevados. O ser humano necessita dar sentido a vida, e isso se traduz em uma dedicação do divino, uma valorização por sobre o que é material, pois o terreno é transitório, mas o divino é eterno (Soares, 2011, p. 112).

Em alguns lugares, este tipo de turismo tem se tornado fator de destaque nos últimos anos, considerando que o turismo religioso é um dos segmentos que mais cresce no cenário do turismo mundial.

Muitos destinos que possuem alguma atividade ou patrimônios culturais voltados para fé e religião se apropriam destes para desenvolver o segmento como mais um fator de diversificação do produto turístico e geração de emprego e renda.

O Festejo de Nossa Senhora da Conceição, movimenta a economia da cidade, além de fazer parte da historia e cultura através da vivência religiosa dos moradores da cidade. No entanto, foi percebido principalmente através dos entrevistados um lamento, quanto à inexistência e a necessidade da história escrita dos festejos em seus primórdios, o que acabou por dificultar as pesquisas para elaboração do presente trabalho.

A memória coletiva do povo de Luís Correia está presente nesse patrimônio imaterial tão rico, visto que 
há mais de um século, mesmo antes de ser cidade e se chamava Vila de Amarração já organizava este evento que hoje se perpetua através das gerações.

Os dados coletados foram analisados de forma descritiva, observando-se os pressupostos destacados por Triviños (2009), de "coerência, consistência, originalidade e objetivação" através das entrevistas.

A pesquisa foi realizada através de entrevistas com duas partes ativas da comunidade católica de Luís Correia, com Padres e alguns moradores da cidade. Sendo realizadas também com pessoas das cidades de Cajueiro da Praia e Parnaíba.

A Festa, atualmente, se caracteriza como um atrativo do segmento de turismo religioso. Muitas cidades que são conhecidas pelo turismo religioso, também não condizem com os conceitos do mesmo, principalmente quanto à utilização dos equipamentos turísticos, agências e pernoite, mas essas são contradições encontradas e discutidas também por muitos autores, que escrevem a respeito do turismo religioso e que parecem estar longe de um consenso. A Festa de Nossa Senhora da Conceição, no entanto, ainda provoca deslocamento de pessoas das comunidades vizinhas de Parnaíba, Cajueiro da Praia e das comunidades da zona rural do município, caracterizando-se como um atrativo religioso atual da cidade. Além disso, movimenta de forma expressiva a economia da cidade com a venda de produtos alimentícios e artesanato.

As motivações dos participantes do evento variam de forma mais expressiva, de acordo com a idade. Os vais jovens vão, pelo lado profano da Festa, vendo a mesma apenas como uma das poucas opções de entretenimento que a cidade oferece de forma fixa. Enquanto, as pessoas de idade mais avançada, participam da Festa, pela devoção, fé e respeito à Santa, pela tradição de veneração aprendida com seus pais e avós ou ainda em busca de fazer penitência e pagar suas promessas em forma de agradecimento. As entrevistas também revelaram que os mais jovens desconhecem a história dos festejos.

A beleza das festas que celebram a religiosidade e os santos católicos nem sempre conserva a autenticidade de suas origens devocionais, mas constitui-se em um dos principais atrativos turísticos do Brasil. No entanto grupos religiosos, compostos por residentes, têm procurado se organizar e adequar para resgatar e perpetuar os ritos simbólicos como forma de manter o sentimento de pertencimento das localidades (Soares, 2011, p 117).

A Festa de Nossa Senhora da Conceição segue a tendência de secularização, focalizando a Festa como um espetáculo, no momento em que muitas são as pessoas que participam dessa para desfrutar de seu lado profano e social, enquanto há pessoas que a veem como uma experiência religiosa tradicional importante, um momento de veneração, devoção e fé.

Quanto ao visitante e/ou turista, alguns vem participar da Festa pela questão de religiosidade, outros por estarem naquele período visitando o município e acabam se deparando com a história e tradição religiosa existente na cidade.

A participação dos moradores devotos de Nossa Senhora da Conceição e de alguns visitantes e turistas, acontece de forma individual e/ou em grupos. Sendo que, de todas as formas de deslocamento, os participantes chegam logo ao anoitecer e retornam para seus lugares de origem após a missa, não utilizando infraestrutura de hospedagem, tão pouco, agências de viagens e turismo. 
Os visitantes e/ou turistas que possuem parentes ou amigos na cidade costumam pernoitar em Luis Correia durante o final de semana que coincide com o período do evento durante a semana estes retornam a seu local de residência.

A massificação da cultura e do turismo se constitui em uma armadilha para a identidade cultural, especialmente das pequenas comunidades. E ai é que reside o paradoxo do turismo, que consiste na reclamação dos moradores quanto à presença dos visitantes, mas, ao mesmo tempo, seu reconhecimento de que sem os visitantes eles não poderiam usufruir as melhorias investidas em seus territórios (Soares, 2011, p. 129).

Como descrito anteriormente, muitas pessoas que participam da Festa se deslocam por motivos exclusivos de fé e devoção. Outros o fazem por entretenimento "O turismo cultura onde se" insere o turismo religioso, possui como objetivo, propiciar experiências que gerem um processo educativo informal, oportunizando o desenvolvimento cultual dos turistas, podendo ter como consequência a preservação do recurso visitado (Costa, 2001 apud Panosso e Gaetta, 2010, p. 173).

\subsection{A FESTA DE NOSSA SENHORA DA CONCEIÇÃO}

A cidade de Luis Correia no estado do Piauí celebra todos os anos a Festa de sua padroeira, Nossa Senhora da Conceição. É um dos principais eventos religiosos do calendário turístico da cidade. Há grande participação da comunidade que se mobiliza para participar do evento numa demonstração de fé e devoção.

A Festa de Nossa Senhora da Conceição é realizada todo ano na Igreja Matriz de 29 de novembro a 08 de dezembro totalizando 10 dias de evento. Nove dias são para as novenas e o décimo dia para a Festa. Durante esse período são realizadas caminhadas, procissões, orações terços, apresentações culturais, bingos, leilões, campanhas para arrecadação de alimentos para doação e missas.

A Festa é organizada pelo Conselho Paroquial, além de outras pessoas da comunidade. Durante as reuniões que acontecem durante os meses que antecedem o evento, várias atividades são desenvolvidas, entre elas: a escolha do tema da festa, as equipes responsáveis por cada comissão, e as funções de cada pessoa dessas equipes, movimentos ou grupos. Uma das equipes é responsável pela arrecadação de recursos financeiros, apoio e patrocínio para arcar com os custos da realização da festa.

Dessa forma, entendemos que um elemento material ou imaterial, tratado como patrimônio herdado pelas populações locais, espelha a identidade da localidade e se constituem um marco referencial para o qual se pode retornar e vivenciar o sentimento de pertencimento. Do mesmo modo, podemos entender que a preservação de tais elementos pode ser assumida como elemento de resiliência que reside em algum ponto do subconsciente coletivo (Soares, 2011 p. 118).

Uma programação é montada, o convite é entregue aos representantes das comunidades do interior, as autoridades da cidade, órgãos, empresas, instituições, escolas, bairros e demais pessoas da cidade. Neste convite também é expresso um pedido, uma colaboração para o "barracão", lugar onde são comercializados bebidas e alimentos. A divulgação também se da através de vinhetas nas rádios, carro de som, de folhetos com a programação do festejo e através das pessoas da própria comunidade. 
As missas são campais, ou seja, são realizadas do lado de fora da igreja. A estrutura montada é com arquibancadas e um altar. A missa não é realizada na igreja, por não comportar o número de participantes.

A programação seguida hoje consiste na abertura da festa com uma alvorada com saída às 05h e carreata pelas principais ruas e bairros da cidade, seguida de café da manhã comunitário no salão paroquial da igreja.

A noite desse mesmo dia é realizada a procissão com o mastro da Santa, que a cada ano sai de um lugar diferente, o que é definido a partir do tema da festa que costuma estar ligado ao tema da campanha da fraternidade da igreja católica.

Com a chegada da procissão na Igreja, o Padre faz a abertura oficial da Festa com a benção e aspersão do mastro com água benta. Este é ornamentado em azul e branco, as cores que representam a imagem de Nossa Senhora da Conceição, em seguida é hasteado com a bandeira de Nossa Senhora, em seguida dá-se início a missa.

Todo o dia realiza-se a procissão com a Imagem de Nossa Senhora da Conceição. Os noitários reúnem-se em frente à igreja, junto à imagem e saem em procissão juntamente com o Padre ou com os padres convidados, os coroinhas e os ministros da eucaristia até chegarem próximo ao altar, onde a imagem é colocada e permanece durante a missa.

Cada dia do evento tem um tema, escolhido pela equipe de liturgia além do símbolo, que pode ser uma imagem, um terço, tudo baseado nas leituras bíblicas do dia. Como são várias pastorais, movimentos, bairros e demais pessoas da comunidade é destinado uma noite para cada um desses convidados. Eles ficam responsáveis pelas leituras e a ornamentação do ambiente onde são celebradas as missas. Também são dedicados um dia para alguns grupos de pessoas da comunidade, as mulheres, os idosos, os pescadores, as famílias, os comerciários e no dia da festa todas as mulheres de nome Maria.

Na cidade ainda há muitas pessoas que criam animais, por isso, um dia da festa é dedicado a eles. O padre lhes dá uma benção e eles saem em seus cavalos em procissão pelas ruas da cidade. Quando estes retornam a praça da igreja, dá-se início a missa, chama-se a "benção dos vaqueiros".

É tradição também fazer em todo festejo de Nossa Senhora da Conceição a caminhada penitencial. Esta, como o próprio nome diz, é realizada para que os fiéis possam pedir perdão pelos seus pecados. $\mathrm{O}$ percurso inicia-se $18 \mathrm{~h}$ do chamado "Morro Branco" que localiza-se na entrada da cidade e vai até a igreja. Durante esta são realizadas 03 paradas para reflexão do tema e oração.

Durante a festa, à benção dos veículos. O padre asperge os carros, motos e bicicletas e estes saem da igreja em procissão pelas principais ruas da cidade e retornam para igreja para dar início à missa.

Há um dia em que os homens ficam responsáveis pela oração do terço denominado "Terço dos Homens", rito esse que se dão todos os dias antes das missas. E um dia dedicado também à adoração ao Santíssimo.

Após as novenas da Santa, no decimo dia acontece a Festa de Nossa Senhora da Conceição. Neste dia centenas de fiéis pagam suas promessas, depositam flores para a santa em agradecimento as graças alcançadas. 
No dia 08 a imagem da Santa tem seu andor todo ornamentado com flores naturais. Que depois são entregues aos fiéis que as levam para suas casas, pois acreditam que essas tem algum de proteção ou benção. Este é o momento de encerramento da Festa, quando as pessoas se dirigem ao andor da Santa, para retirar as flores, rezar e tirar fotos.

À noite acontece a festa que se inicia com a saída em procissão da imagem de Nossa Senhora da Conceição pelas ruas da cidade. O percurso não necessariamente é o mesmo a cada ano. Tão logo a procissão chega à praça da igreja. A imagem é recebida com queima de fogos e a missa de encerramento começa.

O momento mais esperado da festa segundo, os fiéis, é quando a imagem é coroada por uma das crianças da comunidade ao som dos dois hinos e a oração de Nossa Senhora da Conceição. Nas palavras de um devoto da Santa, "é um momento muito bonito e emocionante, chega a arrepiar, é como se pudéssemos sentir a presença da santa no momento da coroação. Mistura-se a beleza do momento com a beleza da música, é realmente mágico. É muito difícil de descrever só vivendo o momento para poder sentir a emoção".

O evento ajuda a movimentar a economia da cidade. Muitos aproveitam a festa para conseguir uma renda extra, através da venda de comida, bebida e artesanato na praça da igreja, para os moradores, visitantes e turistas.

A festa de Nossa Senhora da Conceição permanece fortalecida e ativa, a vivência religiosa dos moradores da cidade de Luís Correia e da região, socializam-se num ambiente de oração e devoção a Santa, mantendo e perpetuando esta prática.

A Festa se realiza de 29 de novembro a 08 de dezembro. É um evento tradicional que a cidade e atrai centenas de fiéis e turistas desde suas primeiras realizações. A manifestação da crença religiosa é expressa de diferentes formas ao redor do mundo e, em cada lugar, incorpora peculiaridades das culturas regionais. As expressões ritualísticas se adaptam, aproximando-se às suas identificações, respeitando as individualidades sem perder o significado da devoção. A forma pode mudar, mas continua transmitindo a mesma mensagem.

\section{CONSIDERAÇÕES FINAIS}

Identificou-se que em Luis Correia a ligação da comunidade com o território se dá por meio de seus ritos religiosos, e a relação de afetividade da comunidade com a Santa vai além do sentimento de patrimônio religioso, cultural e turístico: é uma afinidade que se sobrepõe à beleza estética do local e a seu significado religioso.

Identifica-se que o turista e o visitante são uma versão contemporânea do peregrino, procurando autenticidade em outras épocas e em outros lugares, distanciados de sua vida cotidiana, demonstrando um especial fascínio pelas vidas reais dos outros. Além do que, durante o evento à utilização total ou parcial dos equipamentos turísticos da cidade, o que caracteriza a Festa de Nossa Senhora da Conceição como um atrativo turístico.

\section{REFERÊNCIAS}


ANDRADE, José Vicente. Turismo: Fundamentos e Dimensões. São Paulo: Ática, 2004.

BUSSONS, Alice Mussulini; HAMABATA, Karla Medeiros; GONÇALVES, Pedro Ivo Ferreira. Importância do turismo para a preservação do patrimônio histórico-cultural. In BAHL, Miguel; MARTINS, Rosilene Conceição Rocha; MARTINS, Sérgio Fernandes. (Org.). O Turismo como Força Transformadora do Mundo Contemporâneo. São Paulo: Roca, 2005. P. 03 a 13.

COSTA, Flavia Roberta. Turismo cultual e comunicação interpretativa, Dissertação de Mestrado, Programa de Pós Graduação em Ciências da Comunicação da ECA/USP. São Paulo, 2001. In: PANOSSO Neto, Alexandre. Gaeta, Cecília. Turismo de Experiência. (Org.) São Paulo, Editora SENAC São Paulo 2010.

PEREIRA, João Baptista Borges (org). Religiosidade no Brasil. São Paulo. Editora Universidade de São Paulo, 2012. 400p.

IBGE, 2010. Disponível em: < http://www.censo2010.ibge.gov.br/sinopse/webservice/frm_piramide.php? codigo $=220770 \&$ corhomem $=3 \mathrm{~d} 4590 \&$ cormulher $=9 \mathrm{cdbfc}$ ) $>$.Acesso em 18 maio. 2011.

LOHMANN, Guilherme; PANOSSO, Alexandre Neto. Teoria do Turismo: conceitos, modelos e sistemas. São Paulo: Aleph, 2008.

MELO, Francisco Paulo de Neto. Evento: de ação, de entretenimento a agente de promoção do patrimônio histórico-cultural. In: FUNARI, Pedro Paulo; PINSKY, Jaime. (Org.). Turismo e patrimônio cultural. 4 Ed. São Paulo: contexto, 2005. P. 53 a 66.

OLIVEIRA, Christian Dennys Monteiro de. Turismo Religioso no Brasil: Construindo um Investimento Sociocultural. In: TRIGO, Luiz Gonzaga Godoi, (Org.). Análises regionais e globais do turismo. São Paulo: Roca, 2005. P. 325 a 344.

PORTUGUEZ, Anderson Pereira. Turismo, planejamento socioespacial e patrimônio histórico-cultural. In: PORTUGUEZ, Anderson Pereira, (Org.). Turismo memória e patrimônio cultural. São Paulo: Roca, 2004.

REIS, Ana Carla Fonseca. Economia da Cultura e desenvolvimento sustentável. O caleidoscópio da cultura. Editora Manole, São Paulo, 2007

RIBEIRO. Cristiane Menezes. Turismo religioso: fé, consumo e mercado. E-Revista Facitec, v.5, n.1, Art.6, ago. Dez 2010.

SOARES, Cristiane. Turismo e Integridade ambiental: Realidades e conflitos na paisagem litorânea (estudo de caso) - Rio de Janeiro: Ed. SENAC Rio, 2011.

TRIVIÑOS, N.S. Introdução à pesquisa em ciências sociais: a pesquisa qualitativa em educação. São Paulo: Atlas, 1987. 
[1] Mestre em Meio Ambiente e Desenvolvimento Regional. Universidade para o Desenvolvimento do Estado e da Região do Pantanal - UNIDERP - e professora efetiva da Universidade Federal do Piauí. Campus Ministro Reis Veloso, Parnaíba

[2] Turismóloga pela Universidade Federal do Piauí.

[3] Doutora em psicanálise pelo Seminário internacional de Teologia, Mestranda em ciências da religião pela Universidade Prebiteriana Mackenzie, diretora do Centro de Pesquisa e Estudos Avançados CEPA.

[4] Professora da Universidade Sant'Anna, capelã do Instituto Dante Pazanese e Hospital do Câncer Dr. ARNALDO - Mestranda em Ciências da religião pela Universidade Presbiteriana Mackenzie

\section{PUBLIQUE SEU ARTIGO CIENTÍFICO EM:}

https://www.nucleodoconhecimento.com.br/enviar-artigo-cientifico-para-submissao 